
\title{
25 Research Soure \\ The Pattern of Leaf N:P Ratio Along Plantation Age: A Global Synthesis
}

Hui Zhang

Zhejiang $A$ and $F$ University

Meng Sun

Zhejiang $A$ and $F$ University

\section{Yuxiang Wen}

Research Institute of Subtropical Forestry Chinese Academy of Forestry

\section{Ran Tong}

Research Institute of Subtropical Forestry Chinese Academy of Forestry

Geoff Wang

Clemson University

\section{Qiqian Wu}

Zhejiang A and F University

\section{Yan Li}

Zhejiang $A$ and $F$ University

\section{Tonggui Wu ( $\square$ wutonggui@caf.ac.cn )}

Research Institute of Subtropical Forestry Chinese Academy of Forestry https://orcid.org/0000-00028775-597X

\section{Research}

Keywords: Leaf N:P ratio, stand age, evergreen and deciduous trees, aridity index, global plantations

Posted Date: November 1st, 2021

DOI: https://doi.org/10.21203/rs.3.rs-988959/v1

License: (c) (i) This work is licensed under a Creative Commons Attribution 4.0 International License. Read Full License 


\section{Abstract \\ Background}

Plant stoichiometry displayed flexible over age sequences in previous studies, but effect of stand age on stoichiometry showed large uncertainties for different plantations at the global scale. In this study, we want to obtain the general pattern of leaf $\mathrm{N}: \mathrm{P}$ ratio for global plantations across age gradients through the compilation and analysis of published data from the individual studies.

\section{Results}

Stand age, together with life forms, and climatic variables strongly affected leaf N:P ratio. This result indicates that the stand age is an indispensable underlying mechanism on stoichiometry. Leaf N:P ratio increased with stand age for all plantations pooled together, revealing the existence of the general pattern in leaf stoichiometry for plantations across age gradients. Leaf N:P ratio exhibited no trend in evergreen trees, but an increasing trend was obtained in deciduous trees along age sequences. Meanwhile, leaf $N: P$ ratio rose with stand age for plantations in humid subtropical regions, but it did not vary in dry temperate regions.

\section{Conclusions}

Our results reveal the effects of age on tree stoichiometry cannot be neglected. These age-related patterns of stoichiometry verified that global plantations changed from $\mathrm{N}$ limitation to $\mathrm{P}$ limitation with increasing stand age, particularly for deciduous plantations and in plantations in humid regions. The study highlights the importance of considering stand age when exploring nutrient patterns in plantations, which contributes to improving the plant stoichiometry theory and offers a guidance for the nutrient management of plantations at regional to global scales.

\section{Introduction}

$\mathrm{N}: \mathrm{P}$ ratio reflects the balance of $\mathrm{N}$ (nitrogen) and $\mathrm{P}$ (phosphorus) for plant growth and development, and it is often used to infer potential nutrient limitations on the primary productivity (Güsewell, 2004; Jiang et al., 2017). Studies conducted during the past two decades confirmed that leaf N:P ratio was significantly impacted by abiotic factors, such as geography, climate, and soil (Reich \& Oleksyn, 2004; Tian et al., 2019; Long et al., 2020; Zhang et al., 2020; Luo et al., 2021). Climates are the most important abiotic factor (Reich \& Oleksyn, 2004; Yue et al., 2017; Tian et al., 2019; Yang et al., 2019; Long et al., 2020; Zhang et al., 2020), and latitudinal, longitudinal, and altitudinal patterns of tree N:P ratio are clarified based on the temperature, moisture, and heat distribution (Reich \& Oleksyn, 2004; Han et al., 2005; Du et al., 2017; Zhang et al., 2018a, c; Hu et al., 2020). 
In addition to abiotic factors, the effects of biotic factors on leaf N:P ratio were also widely reported (Chen et al., 2013; Zhang et al., 2016; Hu et al., 2018; Li et al., 2019). These biotic factors included growth forms, taxonomy, species, and organs (Yang et al., 2015; Zhang et al., 2018c; Urbina et al., 2017). However, in most of these studies, age was not considered. Photosynthetic capacity (Zheng et al., 2011) and nutrient requirements (Zhang et al., 2018b) generally vary with plant growth, especially for woody plants or trees. Trees at different growth stages have huge differences in physiological processes and nutrition requirements, resulting in tree nutrient stoichiometry changes along an age sequence (Yan et al., 2018; Zhang et al., 2018b). However, it remains unclear whether age variables should be introduced to analyze the patterns of tree stoichiometry across a large scale.

In the early stage as seedling and saplings, trees grow slowly with small biomass production but have a potent ability to undergo cell division, and thus requires a large amount of protein, resulting in relatively high nitrogen $(\mathrm{N})$ concentration in tree leaves (Gorokhova \& Kyle, 2002; Liu et al., 2016). In the middle stage as young adults, trees grow rapidly with high biomass productions, and need more RNA, DNA, and ATP to participate in photosynthetic assimilation (Agren et al., 2012), and produce the high phosphorus (P) concentration (Li et al., 2017). In the stages of maturity and senility, trees degrade gradually due to the change of physiological function from active to passive (Wang et al., 2015), generating the low tree $P$ concentrations (Zhang et al., 2018b). Therefore, it would be expected that changes in physiological process and nutrition requirement would induce the variation in tree stoichiometry along age sequences.

During the past decades, numerous studies have been conducted to examine the patterns of tree (especially for leaves, the metabolically active organ) N:P ratio along age sequences of pure plantations (Liu et al., 2016; Cao \& Chen, 2017; Chang et al., 2017; Chen et al., 2018; Zhang et al., 2018b), but the results from these studies are highly variable. For example, leaf $\mathrm{N}: \mathrm{P}$ ratio significantly increased with age for Larix kaempferi (Yan et al., 2018), but it showed a first downward, then upward trend for Pinus massoniana (Liu et al., 2016). Yet, leaf N:P ratio remained constant from the young to the over-mature stage for Cunninghamia lanceolata (Zhou et al., 2016). These inconsistent results indicate that a comprehensive understanding of leaf N:P pattern over age sequences remains elusive.

Forest plantations now cover about 291 million hectares globally (FAO, 2020). These plantations often encounter the unbalance between nutrient supplies and requirements for tree growth (Peri et al., 2006; Sun et al., 2016). As described above, previous analyses were conducted for individual species, which showed relatively large uncertainties on the trends of leaf N:P ratio with stand age, and a synthesis for global plantations has not yet been attempted. In this study, we explored the general pattern of leaf N:P ratio for global plantations across age gradients through the compilation and analysis of published data from the individual studies. Specifically, we want to determine whether stand age is a nonnegligible factor on leaf N:P ratio for global plantations. By clarifying the effect of age on tree stoichiometry, the study would contribute to improve the plant stoichiometry theory and provide a theoretical direction in the nutrient management of global plantations in the future.

\section{Materials And Methods}




\section{Data collection}

We compiled a database of published papers from the literature that reported $\mathrm{N}$ and $\mathrm{P}$ dynamics during forest stand development (Appendix S1). To avoid bias in reference selection, we collected data on $\mathrm{N}$ and $P$ concentrations and N:P ratio based on the following three criteria: (1) plantations across world; (2) leaf $\mathrm{N}$ and $\mathrm{P}$ concentrations or N:P during plantation development; (3) quantitative information on stand age. Based on these standards, a total of 192 observations of 31 species ( 16 for evergreen trees and 15 for deciduous trees) related to leaf N:P ratio was taken from 32 papers (see the database).

The raw data were either extracted from published tables or obtained by digitizing published graphs using Engauge Digitizer (Free Software Foundation, Inc., Boston, MA, USA). The entire database was comprised of geographic locations (longitude and latitude), climatic information (mean annual temperature (MAT), mean annual precipitation (MAP) and aridity index (AI)), life forms (evergreen or deciduous trees), stand age, and six target variables that described N, P concentrations, and N:P in leaves and soils. All original data on $\mathrm{N}$ and $\mathrm{P}$ concentrations were converted to standard units $\left(\mathrm{g} \mathrm{kg}^{-1}\right)$. To increase the comparability of data derived from different studies, the original soil $\mathrm{N}$ and $\mathrm{P}$ data were converted to the soil $\mathrm{N}$ and $\mathrm{P}$ concentrations in the top $30 \mathrm{~cm}$. For the threshold data about geographic and climatic information, we used the median value.

The humid or arid conditions were sorted out based on the generalized climate classification scheme for Global-Aridity values. The aridity index value $(\mathrm{Al})>0.65$ represents humid climates, and $\mathrm{Al}<0.65$ reports the climate class from dry sub-humid to hyper-arid (Trabucco \& Zomer, 2009). Al values were extracted from a global climate dataset with a resolution of $0.0083 \times 0.0083(\mathrm{ca} .1 \mathrm{~km} \times 1 \mathrm{~km})$ obtained from http://www.csi.cgiar.org. Both MAT and MAP values were originated from published papers.

\section{Statistical analysis}

Data were processed in the following two steps. Firstly, by synthesizing diverse data from individual studies, we analyzed the patterns of leaf N:P ratio with stand age. Standardized Major Axis (SMA) was used to test for statistical differences in regression lines among life forms and climates. Secondly, the structural equation model (SEM) was used to investigate the relative importance and the direct and indirect effects of stand age, life forms, climatic factors, soil N:P ratio on leaf N:P ratio. All statistical analyses were conducted using the software R 3.5.1 (R Development Core Team).

\section{Results}

\section{Variations of leaf $\mathrm{N}: \mathrm{P}$ ratio across stand age}

Leaf N:P ratio increased with stand age for all plantations pooled together $(P<0.05$, Fig. 1$)$. SEM had an adequate fit (Chi-square $/ \mathrm{df}=0.98, P=0.43$, RMSEA $=0.00$ ) for leaf $\mathrm{N}: \mathrm{P}$ ratio for all plantations (Fig. 2 ). Overall, stand age, as well as life forms, climates strongly affected leaf N:P ratio $(P<0.05)$.

\section{Effects of life forms on leaf $\mathrm{N}: \mathrm{P}$ ratio across stand age}


Leaf $\mathrm{N}: \mathrm{P}$ ratio also increased in deciduous trees across stand age $(P<0.05$, Fig. 3a), and the resulted SMA slope of 0.50 did not differ $(P=0.46)$ from that of all plantations (slope $=0.58)$. However, no trend was found in evergreen plantations ( $P>0.05$, Fig. 3b).

\section{Effects of climates on leaf N:P ratio across stand age}

Leaf N:P ratio distinctly rose with stand age for plantations in humid regions $(P<0.05$, Fig. 4a), but it did not vary in dry sub-humid and hyper-arid regions $(P>0.05$, Fig. $4 \mathrm{~b})$. SMA slope was 0.52 for plantations in humid regions, which was not significantly different from 0.58 for all plantations $(P=0.36)$.

\section{Discussion}

To our knowledge, this study provided the most comprehensive evaluation to date for the pattern of leaf $\mathrm{N}: \mathrm{P}$ ratio for global plantations across ages. In this study, stand age was introduced into the analysis together with life forms, climatic variables, and soil nutrients, we found that stand age had a strong positive effect on leaf $\mathrm{N}: \mathrm{P}$ ratio. The result proved that tree development affected leaf $\mathrm{N}: \mathrm{P}$ ratio, thus confirming that the age variable should be considered in the study on tree stoichiometry. This study is an extension of control factors for the variations in tree stoichiometry.

Leaf N:P ratio increased over age sequences for all plantations pooled together, revealing that there exists a generalized pattern of tree stoichiometry over age sequences for global plantations. The pattern revealed in our study may be explained by different nutrient requirements during different developmental stage. Young trees required more allocation to P-rich ribosomal RNA in support of faster growth rates and high biomass productions (Elser et al., 2010; Agren et al., 2012; Li et al., 2017), which resulted in low N:P ratio due to high $\mathrm{P}$ concentration. While mature or older trees may have an intrinsic ability to decline $\mathrm{P}$ acquisition and prevent progressive P limitation during long-term stand development (Zhang et al., $2018 b)$. This also verified that mature and older trees characterized by lower growth rates tend to be more conservative nutrient requirements comparing to young trees. Thereby, the result revealed leaf N:P ratio was constrained by physiological processes that appeared to correlate with tree growth that is dependent on tree age.

Meanwhile, the increasing leaf N:P ratio suggests that $P$ limitation increases with stand age. In this study, we found that soil N:P ratio increased across age gradients (Appendix S2), reflecting a decrease of soil P concentration with the increasing stand age. This suggests a transition from $\mathrm{N}$ limitation to $\mathrm{P}$ limitation during stand development. The result verified that insufficient soil P supply was the limitation on leaf $N$ :P ratio, supported by the significant relationships between soil and leaf $P$ concentration (Appendix S3). The insufficient soil $P$ supply was caused in part by the $P$ source, which was the input of $P$ to the soils mainly comes from rock weathering with an extremely slow rate (Yan et al., 2018), and in part by $\mathrm{N}$ nutrient dilution due to more $\mathrm{N}$ return relying on the increasing proportion of litter productions during stand development (Zhang et al., 2018b). Taken together, our results indicate that the nutrient limitation of global plantations changed from $\mathrm{N}$ limitation to $\mathrm{P}$ limitation with the increasing stand age. 
Plantations were categorized into evergreen and deciduous groups, we found that leaf N:P ratio exhibited different trends across age gradients between the two groups. No trend was found in evergreen plantations, whereas an increasing trend was obtained in deciduous plantations. The discrepancies may

be due to deciduous trees generally have higher growth rates despite relative shorter growth duration than evergreen trees in juvenile periods (Qi et al., 2020). High growth rates of deciduous trees relate to their higher photosynthesis rates and nutrient-use efficiencies (Field \& Mooney, 1986; Qi et al., 2020). This produces luxury N and P nutrients consumptions (Aerts, 1990; Curtis \& Ackerly, 2008; Silva et al., 2015). With stand aging, the shortage of nutrients supply emerges (Appendix S2), and then affecting leaf N:P ratio of deciduous plantations (Appendix S3). The result shows deciduous trees will be subjected to $P$ limitation over age sequences, furthermore, it implies that deciduous plantations may degrade faster and have shorter longevity than evergreen plantations due to the worse P-restricted situation. This also suggests age index cannot be neglect in these studies of variations in nutrients stoichiometry for deciduous trees.

Besides, the SEM analysis showed that climate variables strongly affected leaf N:P ratio. To suppress the interference of climates, the plantation locations were divided into humid and dry regions based on the aridity index, because aridity is usually expressed as a generalized function of precipitation and temperature (Trabucco \& Zomer, 2009). In our data, the humid regions represent the subtropical sites, and the dry region was in the temperate areas (see the Database). We observed that leaf N:P ratio distinctly rose with stand age for plantations in humid/subtropical regions, but a clear pattern in dry/temperate regions was not detected. This indicates that plantations are solely subjected to $\mathrm{P}$ limitation over age sequences in subtropical areas with plentiful rainfall. The result is consistent with the view that $P$ nutrient resources restricted plant growth in humid regions with abundant water supplies (Du et al., 2020). Therefore, our study confirms that stand age is liable for plant stoichiometry in humid but not in dry regions.

Beyond to the contribution towards the stoichiometry theory, our results should also provide practical guidance to nutrient management. Because our study revealed that global plantations suffered from $P$ deficiency during stand development, especially for deciduous plantations or plantations in humid subtropical regions, $P$ fertilizer should be an appropriate way to cope with the nutrient limitation for mature and over-mature plantations in humid subtropical regions. In the future, afforestation should also select the proper species that are able to cope with $\mathrm{P}$ shortage with the advance of stand development, such as planting more evergreen species.

\section{Conclusion}

In summary, our analyses indicate the existence of the general pattern in leaf N:P ratio for plantations across the age gradient. Stand age was the underlying mechanism affecting this stoichiometry. These results have important implications for our understanding of age-patterns in plant stoichiometry and offer a promise for the nutrient management of plantations at global scales. 


\section{Declarations}

\section{Ethics approval and consent to participate}

Not applicable.

\section{Consent for publication}

Not applicable.

\section{Availability of data and material}

All data generated or analyzed during this study are included in this published article and its supplementary information files.

\section{Competing interests}

The authors declare that they have no competing interests.

\section{Funding}

This work was financially supported by the National Natural Science Foundation of China (42001046, 41730638), and Scientific Research Foundation of Zhejiang A\&F University (303-1011200017).

\section{Authors' contributions}

$H Z$, YL and TW planned the study; $H Z, M S, Y W$ and RT collected raw data; $H Z$ and QW performed all statistical analyses; $\mathrm{HZ}, \mathrm{GW}$ and TW contributed the writing of the manuscript. The authors read and approved the final manuscript.

\section{Acknowledgements}

We thank authors of all referenced publications for providing the original information as well as the reviewers for their comments and suggestions.

\section{References}

1. Aerts R (1990) Nutrient use efficiency in evergreen and deciduous species from heathlands. Oecologia 84(3): 391-397.

2. Agren GI, Wetterstedt JAM, Billberger MFK (2012) Nutrient limitation on terrestrial plant growthModeling the interaction between nitrogen and phosphorus. New Phytol 194: 953-960.

3. Cao Y, Chen YM (2017) Coupling of plant and soil C:N:P stoichiometry in black locust (Robinia pseudoacacia) plantations on the Loess Plateau, China. Trees 31: 1559-1570. 
4. Chang Y, Li N, Wang W, Liu X, Du F, Yao D (2017) Nutrients resorption and stoichiometry characteristics of different-aged plantations of Larix kaempferi in the Qinling Mountains, central China. PLoS ONE 12(12): e0189424.

5. Chen LL, Deng Q, Yuan ZY, Mu XM, Kallenbache RL (2018) Age-related C:N:P stoichiometry in two plantation forests in the Loess Plateau of China. Ecol Eng 120: 14-22.

6. Chen Y, Han W, Tang L, Tang Z, Fang J (2013) Leaf nitrogen and phosphorus concentrations of woody plants differ in responses to climate, soil and plant growth form. Ecography 36: 178-184.

7. Curtis PS, Ackerly DD (2008) Introduction to a virtual special issue on plant ecological strategy axes in leaf and wood traits. New Phytol 179: 901-903.

8. Du BM, Ji HW, Peng C, Liu XJ, Liu CJ (2017) Altitudinal patterns of leaf stoichiometry and nutrient resorption in Quercus variabilis in the Baotianman Mountains, China. Plant Soil 413: 193-202.

9. Du E, Terrer C, Pellegrini AFA. Ahlström A, van Lissa CJ, Zhao X, Xia N, Wu X, Jackson RB (2020) Global patterns of terrestrial nitrogen and phosphorus limitation. Nat Geosci 13: 221-226.

10. Elser JJ, Fagan WF, Kerkhoff AJ, Swenson NG, Enquist BJ (2010) Biological stoichiometry of plant production: metabolism, scaling and ecological response to global change. New Phytol 186: 593608.

11. FAO (2020) Global Forest resources Assessment 2020 - Key findings. Rome.

12. Field C, Mooney HA (1986) The photosynthesis-nitrogen relationship in wild plants. In Givnish, T.J. (Ed.). On the economy of plant form and function, pp. 25-55. Cambridge University Press, Cambridge, U.K.

13. Gorokhova E, Kyle M (2002) Analysis of nucleic acids in daphnia: development of methods and ontogenetic variations in RNA-DNA content. J Plankton Res 24: 511-522.

14. Güsewell S (2004) N:P ratios in terrestrial plants: variation and functional significance. New Phytol 164: 243-266.

15. Han WX, Fang JY, Guo DL, Zhang Y (2005) Leaf nitrogen and phosphorus stoichiometry across 753 terrestrial plant species in China. New Phytol 168: 377-385.

16. Hu MJ, Peñuelas J, Sardans J, Sun ZG, Wilson BJ, Huang JF, Zhu QL, Tong C (2018) Stoichiometry patterns of plant organ $\mathrm{N}$ and $\mathrm{P}$ in coastal herbaceous wetlands along the East China Sea: implications for biogeochemical niche. Plant Soil 431: 273-288.

17. Hu QJ, Sheng MY, Bai YX, Jie Y, Xiao HL (2020) Response of C, N, and P stoichiometry characteristics of Broussonetia papyrifera to altitude gradients and soil nutrients in the karst rocky ecosystem, SW China. Plant Soil doi.org/10.1007/s11104-020-04742-7.

18. Jiang P, Chen Y, Cao Y (2017) C:N:P stoichiometry and carbon storage in a naturally-regenerated secondary Quercus variabilis forest age sequence in the Qinling mountains, China. Forests 8: 281.

19. Li HL, James M, Crabbe C, Xu FL, Wang WL, Niu RL, Gao X, Zhang P, Chen HK (2017) Seasonal variations in carbon, nitrogen and phosphorus concentrations and $\mathrm{C}: \mathrm{N}: \mathrm{P}$ stoichiometry in the leaves of differently aged Larix principis-rupprechtii Mayr. plantations. Forests 8: 373. 
20. Li M, Huang C, Yang T, Drosos M, Wang J, Kang X, Liu F, Xi B, Hu Z (2019) Role of plant species and soil phosphorus concentrations in determining phosphorus: nutrient stoichiometry in leaves and fine roots. Plant Soil 445: 231-242.

21. Liu JT, Gu ZJ, Shao HB, Zhou F, Peng SY (2016) N-P stoichiometry in soil and leaves of Pinus massoniana forest at different stand ages in the subtropical soil erosion area of China. Environ Earth Sci 75: 1091.

22. Long M, Zhang J, Liu Z, Zhou L, Su F, Xiao R, Wang Y, Guo H, Hu S (2020) Can the scaling of plant nitrogen to phosphorus be altered by global change? An empirical test. J Plant Ecol 13: 442-449.

23. Luo Y, Peng Q, Li K, Gong Y, Liu Y, Han W (2021) Patterns of nitrogen and phosphorus stoichiometry among leaf, stem and root of desert plants and responses to climate and soil factors in Xinjiang, China. Catena 199: 105100.

24. Peri PL, Gargaglione V, Pastur GM (2006) Dynamics of above- and below-ground biomass and nutrient accumulation in an age sequence of Nothofagus antarctica forest of Southern Patagonia. Forest Ecol Manag 233: 85-99.

25. Qi JH, Fan ZX, Fu PL, Zhang YJ, Sterck F (2020) Differential determinants of growth rates in subtropical evergreen and deciduous juvenile trees: carbon gain, hydraulics and nutrient-use efficiencies. Tree Physiol 41: 12-23.

26. Reich PB, Oleksyn J (2004) Global patterns of plant leaf $N$ and $P$ in relation to temperature and latitude. PNAS 101: 11001-11006.

27. Silva JO, Espírito-Santo MM, Morais HC (2015) Leaf traits and herbivory on deciduous and evergreen trees in a tropical dry forest. Basic Appl Ecol 16: 210-219.

28. Sun ZZ, Liu LL, Peng SS, Peñuelas J, Zeng H, Piao SL (2016) Age-related modulation of the nitrogen resorption efficiency response to growth requirements and soil nitrogen availability in a temperate pine plantation. Ecosystems 19: 698-709.

29. Tian DS, Reich PB, Chen HYH, Xiang YZ, Luo YQ, Shen Y, Meng C, Han WX, Niu SL (2019) Global changes alter plant multi-element stoichiometric coupling. New Phytol 221: 807-817.

30. Trabucco A, Zomer RJ (2009) Global aridity index (Global-Aridity) and global potential evapotranspiration (Global-PET) geospatial database. CGIAR Consortium for Spatial Information.

31. Urbina I, Sardans J, Grau O, Beierkuhnlein C, Jentsch A, Kreyling J, Peñuelas J (2017) Plant community composition affects the species biogeochemical niche. Ecosphere 8(5): e01801.

32. Wang Z, Lu J, Yang M, Yang H, Zhang Q (2015) Stoichiometric characteristics of carbon, nitrogen, and phosphorus in leaves of differently aged Lucerne (Medicagosativa) stands. Front Plant Sci 6: 1062.

33. Yan T, Lü XT, Zhu JJ, Yang K, Yu LZ, Gao T (2018) Changes in nitrogen and phosphorus cycling suggest a transition to phosphorus limitation with the stand development of larch plantations. Plant Soil 422: 385-396.

34. Yang X, Huang Z, Zhang K, Cornelissen JHC (2015) C:N:P stoichiometry of Artemisia species and close relatives across northern China: unraveling effects of climate, soil and taxonomy. J Ecol 
103(4): 1020-1031.

35. Yang YZ, Wang H, Harrison SP, Prentice IC, Wright IJ, Peng CH, Lin GH (2019) Quantifying leaf-trait covariation and its controls across climates and biomes. New Phytol 221: 155-168.

36. Yue K, Fornara DA, Yang WQ, Peng Y, Li ZJ, Wu FZ, Peng CH (2017) Effects of three global change drivers on terrestrial C:N:P stoichiometry: a global synthesis. Global Change Biol 23: 2450-2463.

37. Zhang H, Guo WH, Wang GG, Yu MK, Wu TG (2016) Effect of environment and genetics on leaf $\mathrm{N}$ and P stoichiometry for Quercus acutissima across China. Eur J Forest Res 135: 795-802.

38. Zhang H, Guo WH, Yu MK, Wang GG, Wu TG (2018a) Latitudinal patterns of leaf N, P stoichiometry and nutrient resorption of Metasequoia glyptostroboides along the eastern coastline of China. Sci Total Environ 618: 1-6.

39. Zhang H, Wang JN, Wang JY, Guo ZW, Wang GG, Zeng DH, Wu TG (2018b) Tree stoichiometry and nutrient resorption along a chronosequence of Metasequoia glyptostroboides forests in coastal China. Forest Ecol Manag 430: 445-450.

40. Zhang JH, Zhao N, Liu CC, Yang H, Li ML, Yu GR, Wilcox K, Yu Q, He NP (2018c) C:N:P stoichiometry in China's forests: From organs to ecosystems. Funct Ecol 32: 50-60.

41. Zhang K, Li MM, Su YZ, Yang R (2020) Stoichiometry of leaf carbon, nitrogen, and phosphorus along a geographic, climatic, and soil gradients in temperate desert of Hexi Corridor, northwest China. $\mathrm{J}$ Plant Ecol 13: 114-121.

42. Zhang Q, Xiong GM, Li JX, Lu ZJ, Li YL, Xu WT, Wang Y, Zhao CM, Tang ZY, Xie ZQ (2018d) Nitrogen and phosphorus concentrations and allocation strategies among shrub organs: the effects of plant growth forms and nitrogen-fixation types. Plant Soil 427: 305-319.

43. Zheng Y, Zhao Z, Zhou JJ, Zhou H, Liang ZS, Luo ZB (2011) The importance of slope aspect and stand age on the photosynthetic carbon fixation capacity of forest: A case study with black locust (Robinia pseudoacacia) plantations on the Loess Plateau. Acta Physiol Plant 33: 419-429.

44. Zhou L, Addo-Danso SD, Wu P, Li S, Zou X, Zhang Y, Ma X (2016) Leaf resorption efficiency in relation to foliar and soil nutrient concentrations and stoichiometry of Cunninghamia lanceolata with stand development in southern China. J Soil Sediment 16: 1448-1459.

\section{Figures}




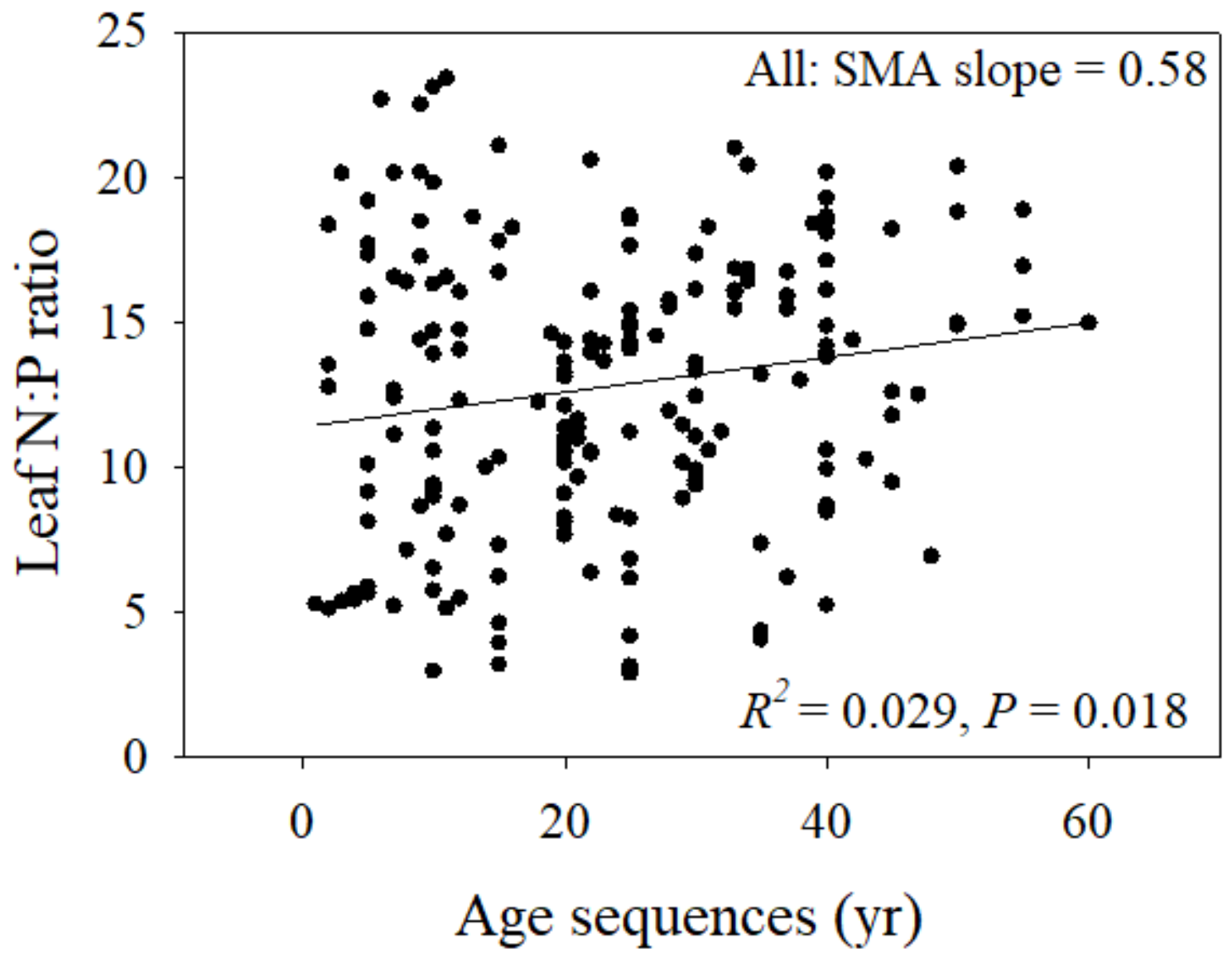

Figure 1

Variations of leaf N:P ratio over age sequences for all trees pooled together. 


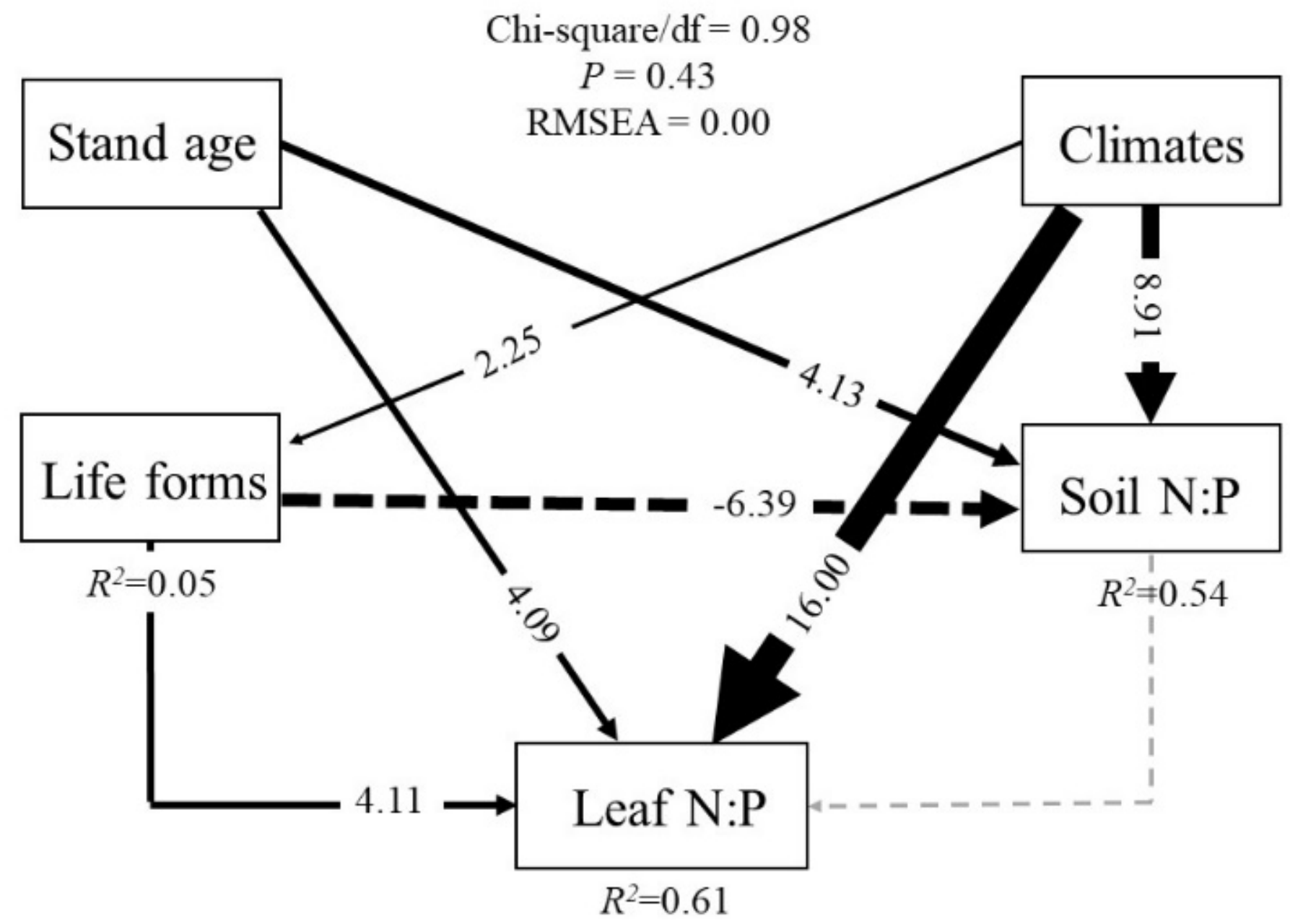

Figure 2

Structural equation model fitted to leaf N:P ratio. Solid, black dashed, and gray dashed arrows represent the significant positive, negative, and unapparent effects, respectively. Line thickness indicates the strength of the causal relationship. Numbers on the arrows are standardized path coefficients and indicative of the effect size of the relationship. Climates, composite variable including latitude, longitude, mean annual temperature and precipitation, aridity index; Life forms, composite variable including evergreen and deciduous trees. 

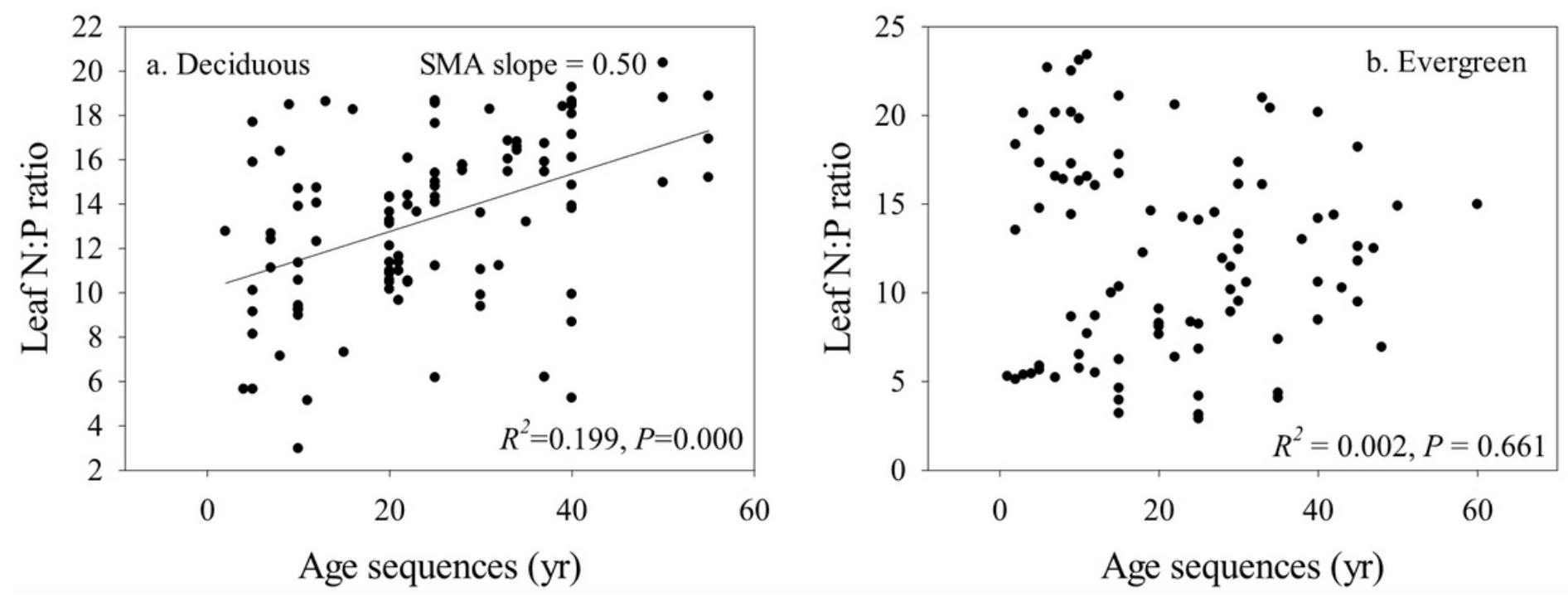

Figure 3

Variations of leaf N:P ratio over age sequences for deciduous (a) and evergreen (b) trees.
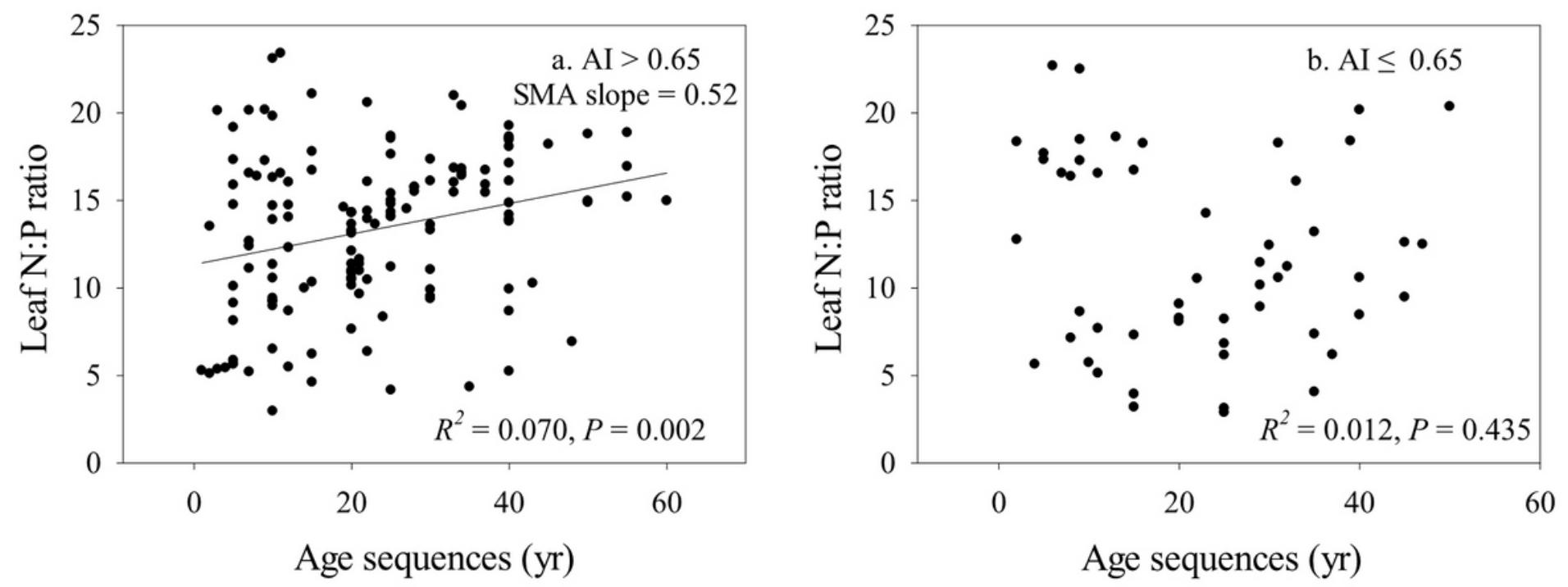

Figure 4 
Variations of leaf $\mathrm{N}: \mathrm{P}$ ratio over age sequences in humid $(\mathrm{a}, \mathrm{Al}>0.65)$ and dry $(\mathrm{b}, \mathrm{Al} \leq 0.65)$, regions. $\mathrm{Al}$, aridity index.

\section{Supplementary Files}

This is a list of supplementary files associated with this preprint. Click to download.

- Database.xls

- SupplementaryData.doc 